\title{
Perfil da meningite na população pediátrica no estado de Minas Gerais, Brasil
}

\author{
Epidemiologic profile of pediatric meningitis cases in Minas Gerais, Brazil
}

\author{
L. P. Figueredo ${ }^{1 *}$; C. M. V. Barreto ${ }^{1}$; W. N. T. Silva ${ }^{1}$; L. F. Barros ${ }^{1}$; G. L. R. \\ Lima $^{1} ;$ R. M. Teixeira ${ }^{1}$; S. V. de Oliveira ${ }^{2}$ \\ ${ }^{1}$ Faculdade de Medicina, Universidade Federal de Uberlândia, 38405-320, Uberlândia-MG, Brasil \\ ${ }^{2}$ Departamento de Saúde Coletiva, Universidade Federal de Uberlândia, 38405-320, Uberlândia-MG, Brasil
}

*Leonardo.anhg@gmail.com

(Recebido em 21 de abril de 2021; aceito em 04 de agosto de 2021)

\begin{abstract}
A meningite é uma doença que decorre da inflamação das meninges e do espaço subaracnóideo, podendo ser causada por bactérias, vírus e outros agentes etiológicos. O objetivo deste estudo foi quantificar e caracterizar os casos de meningite no estado de Minas Gerais (MG). Trata-se de um estudo epidemiológico da meningite pediátrica (0 a 14 anos) notificada ao Sistema de Informação de Agravos de Notificação (SINAN) no período de 2010 a 2019. Foram registrados casos no período de estudo, a incidência média de casos foi de 10,32 casos a cada 100 mil habitantes e uma letalidade de 7,86\%. Por meio da análise, observou-se que entre 2010 e 2019, houve uma queda de $36 \%$ para o número de casos e de 55\% para o número de óbitos causados pela meningite, além da redução da incidência (-16\%) e da letalidade (-40\%). Também se constatou maior letalidade em crianças menores de 1 ano, e predomínio de casos em zonas urbanas e em cidades maiores de MG. As principais etiologias da meningite identificadas no estudo foram a viral (37\%), não especificada (27\%) e bacteriana (16\%), respectivamente. Após uma comparação dos dados encontrados com outras informações da literatura científica, concluiu-se que a meningite ainda é um problema evidente em MG e que a grande porcentagem da não-especificação das etiologias da doença limita estudos epidemiológicos e reflete em problemas diagnósticos e dificuldades na promoção da saúde.
\end{abstract}

Palavras-chave: vigilância em saúde, Epidemiologia, promoção da saúde.

Meningitis is a disease that results from inflammation of the meninges and the subarachnoid space and can be caused by bacteria, viruses and other etiologic agents. The objective of this study was to quantify and characterize the cases of meningitis in the state of Minas Gerais (MG). This is an epidemiological study of pediatric meningitis (0 to 14 years old) notified to the Notifiable Diseases Information System known as SINAN in the period from 2010 to 2019. The average incidence of cases during the study period was 10.32 cases per 100 thousand inhabitants and the lethality was $7.86 \%$. Through the analysis, it was observed that between 2010 and 2019, there was a decrease of 36\% for the number of cases and 55\% for the number of deaths caused by meningitis, in addition to a reduction in the incidence (-16\%) and lethality $(-40 \%)$. There was also a higher lethality in children under 1 year of age, and a predominance of cases in urban areas and in larger cities in MG. The main etiologies of meningitis identified in the study were viral (37\%), not found (27\%) and bacterial (16\%), respectively. After analyzing the data, we concluded that meningitis is still an evident problem in MG and that the large percentage of unidentified etiology limits epidemiological studies and demonstrates diagnostic problems and difficulties in health promotion.

Keywords: health vigilance, Epidemiology, health promotion.

\section{INTRODUÇÃO}

Meningite é o termo médico usado para descrever o processo inflamatório das meninges e espaço subaracnóideo, com potencial de se estender ao córtex cerebral e parênquima [1]. Pode ser dividida em meningite bacteriana, caracterizada como uma pleocitose no líquido cefalorraquidiano (LCR) com crescimento bacteriano [1], e em meningite asséptica, quando a pleocitose no LCR se desenvolve na ausência de bactérias [2], onde, apesar de discordâncias presentes na literatura [3], a maioria dos autores consideram os vírus (meningite viral) como seu principal representante [4-6]. As meningites bacteriana e viral acometem todas as faixas etárias, 
entretanto por características fisiológicas, a faixa pediátrica se torna bastante suscetível à essa afecção [7]. Outros inúmeros fatores de risco estão associados a esse grupo, como idade gestacional, estações do ano, número de crianças na família [8], ausência de imunização [9] e anemia falciforme [10].

No contexto pediátrico, as bactérias são conhecidas por desenvolverem os quadros mais graves de meningite [11], apresentando altas taxas de letalidade ao redor do mundo [9]. A epidemiologia da doença mostra que os agentes bacterianos tendem a se tornarem mais frequentes dependendo da faixa etária do indivíduo, destacando-se o S. pneumoniae (pneumococo) em crianças menores de 5 anos de idade, e a N. Meningitidis (meningococo), em crianças mais velhas, adolescentes e adultos jovens [1]. Por outro lado, a meningite viral, caracteriza-se como a forma mais comum dentre as meningites em crianças, normalmente associada a bons prognósticos e baixas taxas de mortalidade [12, 13]. Os enterovírus, herpesvírus e arbovírus (transmitidos por artrópodes) são os principais agentes virais conhecidos por incidirem sobre essa faixa etária [13].

Os sinais e sintomas clínicos das meningites bacteriana e viral são variados e dependem de fatores como a idade da criança, seu estado imunológico, o patógeno e a duração da doença [4, 14]. Os sinais clínicos não específicos podem se manifestar como febre, cefaléia, náuseas, vômitos, taquicardia, letargia, falta de apetite, dor nas pernas e, em estágios avançados, sinais de grave comprometimento neurológico e sepse fulminante, sendo o último, vinculado a meningite bacteriana. Os sinais de Kernig e Brudzinski positivos, rigidez de nuca, fotofobia e abaulamento da fontanela são conhecidos como os sinais clássicos da doença $[4,14]$. Porém, pelos achados clínicos serem inconfiáveis e muito parecidos [6], o padrão ouro para se confirmar o quadro de meningite e diferenciá-lo etiologicamente está na análise do LCR [1].

Quanto ao tratamento, a antibioticoterapia deve ser realizada em pacientes com meningite bacteriana, porém, dada a sua acentuada taxa de mortalidade e potencial de acarretar sequelas neuropsicológicas graves, a administração medicamentosa deve ser iniciada antes dos resultados da análise do LCR, e, em seguida, otimizada e direcionada após correta confirmação e identificação do agente bacteriano [1,6]. Caso a meningite seja de origem viral, a maioria dos pacientes são adequadamente submetidos a terapia de suporte [4].

Em um caráter preventivo, o desenvolvimento de vacinas para patógenos específicos foi o principal fator de mudança nos dados epidemiológicos de meningite nos países desenvolvidos $[15,16]$. Similarmente, no Brasil, isso foi demonstrado depois que dados do Ministério da Saúde apontaram diminuição no número de casos de meningite bacteriana nos anos de 1999, onde fora disponibilizada a vacina contra o H. influenzae (Hib) [16, 17], e em 2010, período em que o país disponibilizou na caderneta de vacinação da criança, a vacina conjugada pneumocócica 10-valente (PCV10) e do grupo C capsular meningocócico (MenC-V) [15, 17].

A partir do exposto, é possível perceber que a meningite se constitui como uma doença agravante na faixa etária pediátrica, relacionando-se com prognósticos desfavoráveis e altas taxas de mortalidade e letalidade, a depender do agente etiológico. Torna-se indispensável o estudo epidemiológico dessa patologia na faixa etária mencionada, servindo-se de ferramenta para a compreensão das particularidades que cada território apresenta, contribuindo para a uma maior racionalização dos métodos de prevenção e tratamento, e para a formulação de políticas públicas mais eficientes.

Desse modo, o objetivo deste estudo foi analisar o perfil epidemiológico dos casos confirmados de meningites bacteriana e viral no estado de Minas Gerais, por meio de um recorte pediátrico.

\section{MATERIAL E MÉTODOS}

O estudo epidemiológico em questão caracterizou-se por ser descritivo e quantitativo; os dados foram obtidos por meio do Sistema de Informação de Agravos de Notificação (SINAN), do qual foram extraídas informações específicas de casos confirmados de meningite bacteriana e viral no Estado de Minas Gerais. A idade dos pacientes esteve no intervalo de 0 a 14 anos, no período de janeiro de 2010 a dezembro de 2019. Foram disponibilizados pelo Ministério da 
Saúde (MS) os dados epidemiológicos solicitados pelo serviço de informação ao cidadão (e-sic) através do sistema eletrônico, com o seguinte protocolo 25820003808202078.

O Estado de Minas Gerais apresenta população estimada em 19.597.330 habitantes, com densidade demográfica de $33,41 \mathrm{hab} . / \mathrm{km}^{2}$, segundo dados divulgados pelo último censo do Instituto Brasileiro de Geografia e Estatística (IBGE).

Em relação aos critérios de inclusão e exclusão, neste estudo, foram incluídos os casos notificados ao MS e disponibilizados no TABNET. As variáveis analisadas foram: Sexo (masculino; feminino), Zona de residência (zona urbana; zona rural; periurbana; ignorado/branco), Raça (branca; preta; amarela; parda; indígena; ignorado/branco), Quantidade de notificações, incidências e letalidades, Etiologia e Sorogrupos (Neisseria meningitidis).

A análise de dados foi realizada por estatística descritiva, apresentando-se números brutos, medidas de frequência e tendência central. Para isso, foram utilizados os softwares Excel e Tabwin. Em relação aos indivíduos em questão (população de 0 a 14 anos, no Estado de Minas Gerais, entre os anos de 2010 a 2019), foram notificados 4.562 casos de meningite; dentre estes ocorreram 365 mortes.

Neste estudo, devido ao fornecimento secundário de dados, sem qualquer indício de identificação dos pacientes, tornou-se desnecessário, por seguimento às normas éticas do país, a submissão ao Comitê de Ética em Pesquisa (CEP), segundo resolução do Conselho Nacional de Saúde $\mathrm{N}^{\circ} 510$, de 7 de abril de 2016.

\section{RESULTADOS}

Foram registrados 4.642 casos de meningite e 365 óbitos entre indivíduos de 0 a 14 anos para o estado de Minas Gerais, de 2010 a 2019. Entre 2010 e 2019 houve queda de $26 \%$ para o número de casos e 55\% para os óbitos, A incidência média foi de 10,32 casos por 100 mil habitantes e a letalidade média foi de 7,86 óbitos por 100 casos da doença. A incidência decresceu $16 \%$ e a taxa de letalidade $40 \%$ (Figura 1).

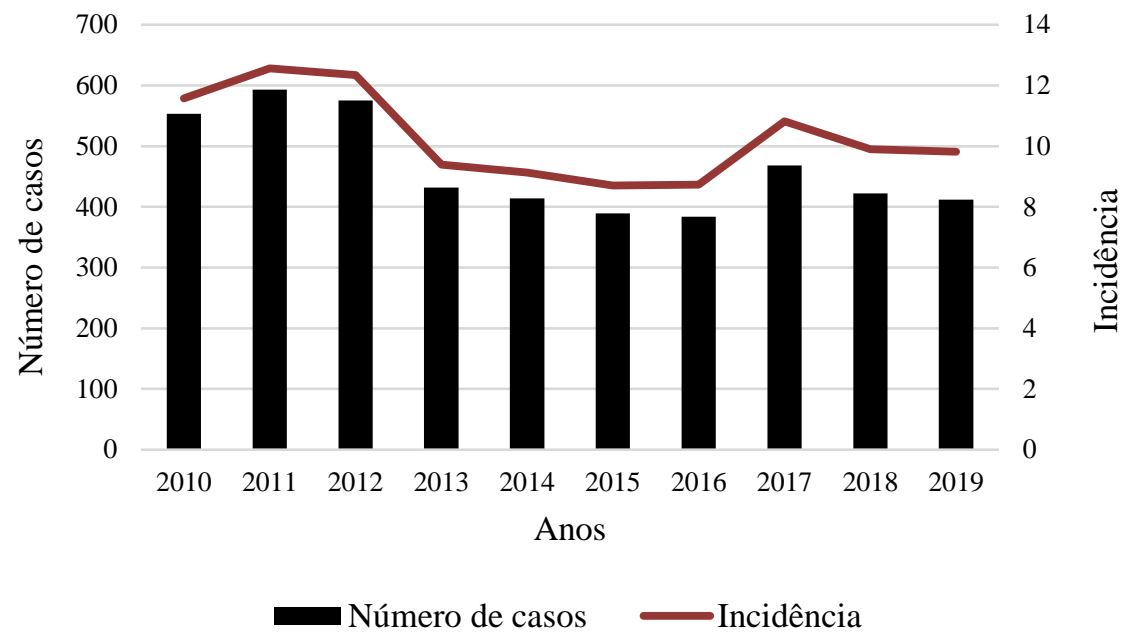

Figura 1: Incidência e número de casos notificados de meningites por ano segundo dados do SINAN, em indivíduos de 0-14 anos, de 2010 a 2019, Minas Gerais, Brasil.

O maior número de casos de meningite foi registrado em dezembro (455) e o menor em fevereiro (287), existindo variações consideráveis ao longo dos meses (Figura 2). 


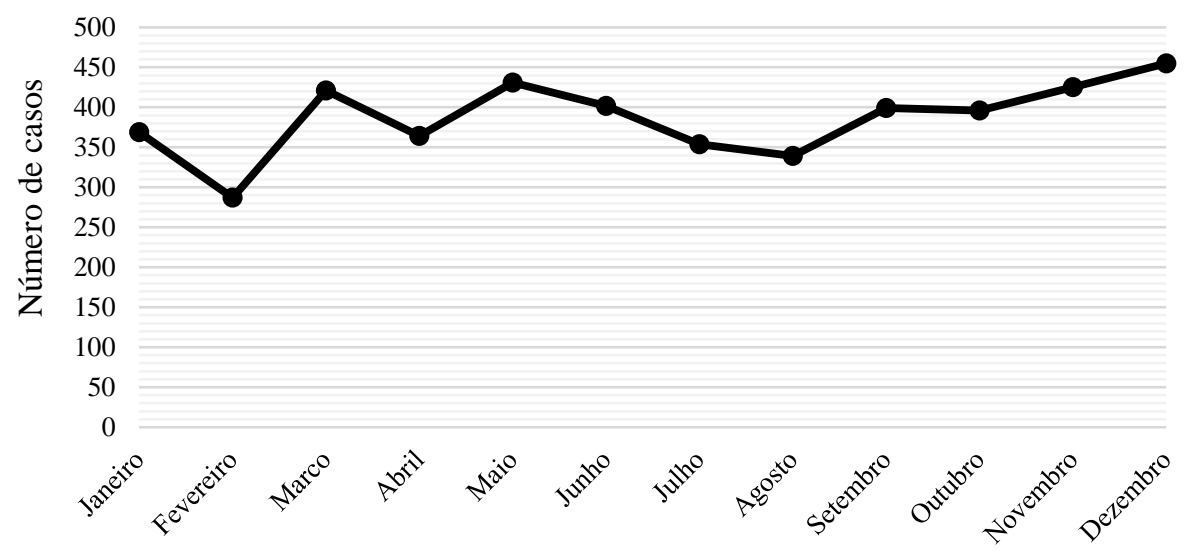

Mês de internação

Figura 2: Número de casos de meningite notificados por mês do ano, segundo dados do SINAN, em indivíduos de 0-14 anos, de 2010 a 2019, Minas Gerais, Brasil.

Os casos apresentaram decréscimo com o avançar da idade. Houve predomínio do sexo masculino para casos $(58,87 \%)$ e óbitos $(51,78 \%)$ (Figura 3). A letalidade foi maior no sexo feminino $(9,2 \%)$ quando comparada ao masculino $(6,9 \%)$ e, dentre as faixas etárias, foi de $9,2 \%$ entre menores de 1 ano, 7,1\% entre indivíduos de 1 a 4 anos, 6,4\% entre aqueles de 5 a 9 anos e $7,9 \%$ entre os que possuíam de 10 a 14 anos.

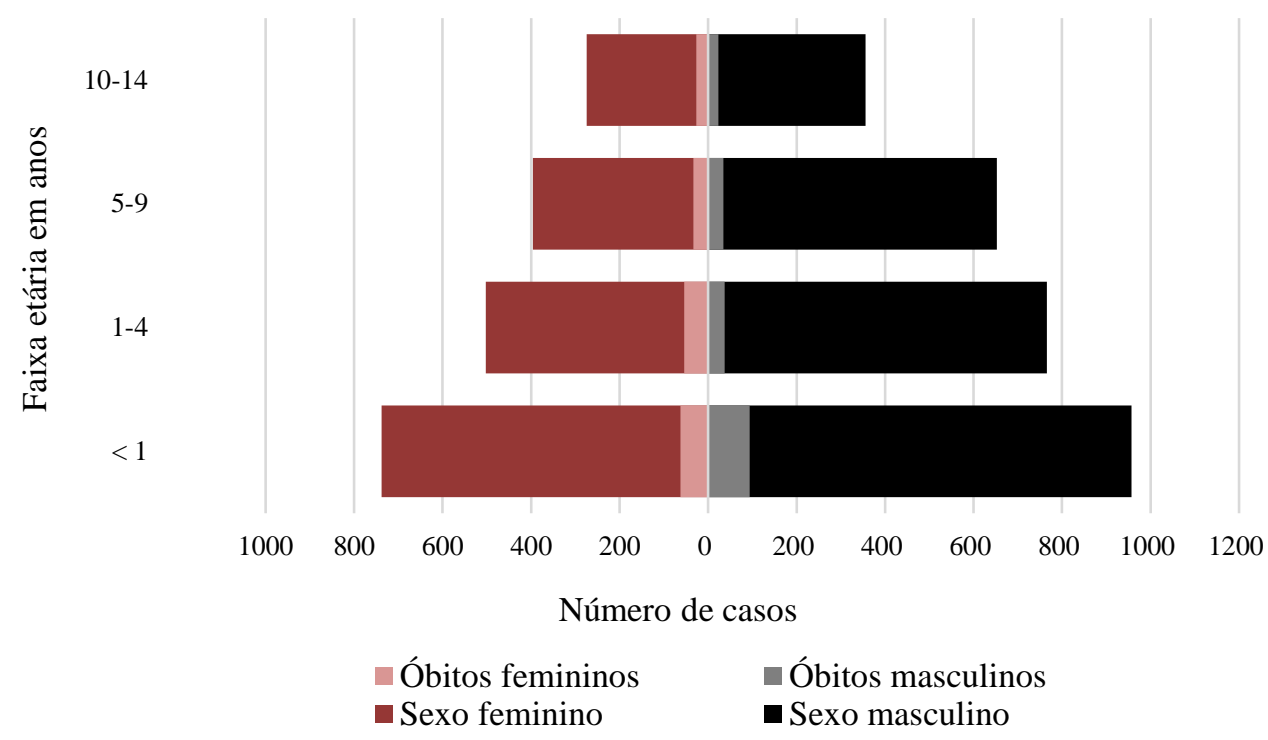

Figura 3: Número de casos de meningite notificados por sexo e faixa etária, segundo dados do SINAN, em indivíduos de 0-14 anos, de 2010 a 2019, Minas Gerais, Brasil.

A zona urbana concentrou a maior parte dos casos e dos óbitos, entretanto, a zona rural apresentou letalidade de 13,3\%, com aproximadamente 6 óbitos a mais a cada 100 doentes do que na zona urbana. Brancos e pardos registraram a maior parte das meningites. Ressalta-se que $28 \%$ dos casos e $24 \%$ dos óbitos possuíam registro incompleto para o critério "raça" (Tabela 1). 
Tabela 1: Número e porcentagem dos casos e óbitos das notificações de meningite por zona de residência e raça, segundo dados do SINAN, em indivíduos de 0-14 anos, de 2010 a 2019, Minas Gerais, Brasil.

\begin{tabular}{lrrrr}
\hline & \multicolumn{2}{c}{ Casos } & \multicolumn{2}{c}{ Óbitos } \\
& N & \% & N & \% \\
\hline Zona de residência & & & & \\
Urbana & 4134 & 89,06 & 309 & 84,66 \\
Rural & 248 & 5,34 & 33 & 9,04 \\
Periurbana & 39 & 0,84 & 2 & 0,55 \\
$\quad$ Ignorado/ branco & 221 & 4,76 & 21 & 5,75 \\
Raça & & & & \\
Branca & 1638 & 35,29 & 126 & 34,52 \\
Preta & 225 & 4,85 & 15 & 4,11 \\
Amarela & 19 & 0,41 & 1 & 0,27 \\
Parda & 1412 & 30,42 & 131 & 35,89 \\
Indígena & 9 & 0,19 & 1 & 0,00 \\
Ignorado/ branco & 1339 & 28,85 & 91 & 24,93 \\
\hline
\end{tabular}

A maior frequência de notificações se deu em Belo Horizonte (819), Uberlândia (645) e Uberaba (310), as quais somam $38 \%$ do total de casos do Estado. As maiores incidências foram registradas em Ingaí, Uberlândia e Uberaba e a maior quantidade de óbitos em Belo Horizonte (49), Uberlândia (18) e Contagem (15). A letalidade foi maior em municípios de menor porte (Figura 4).
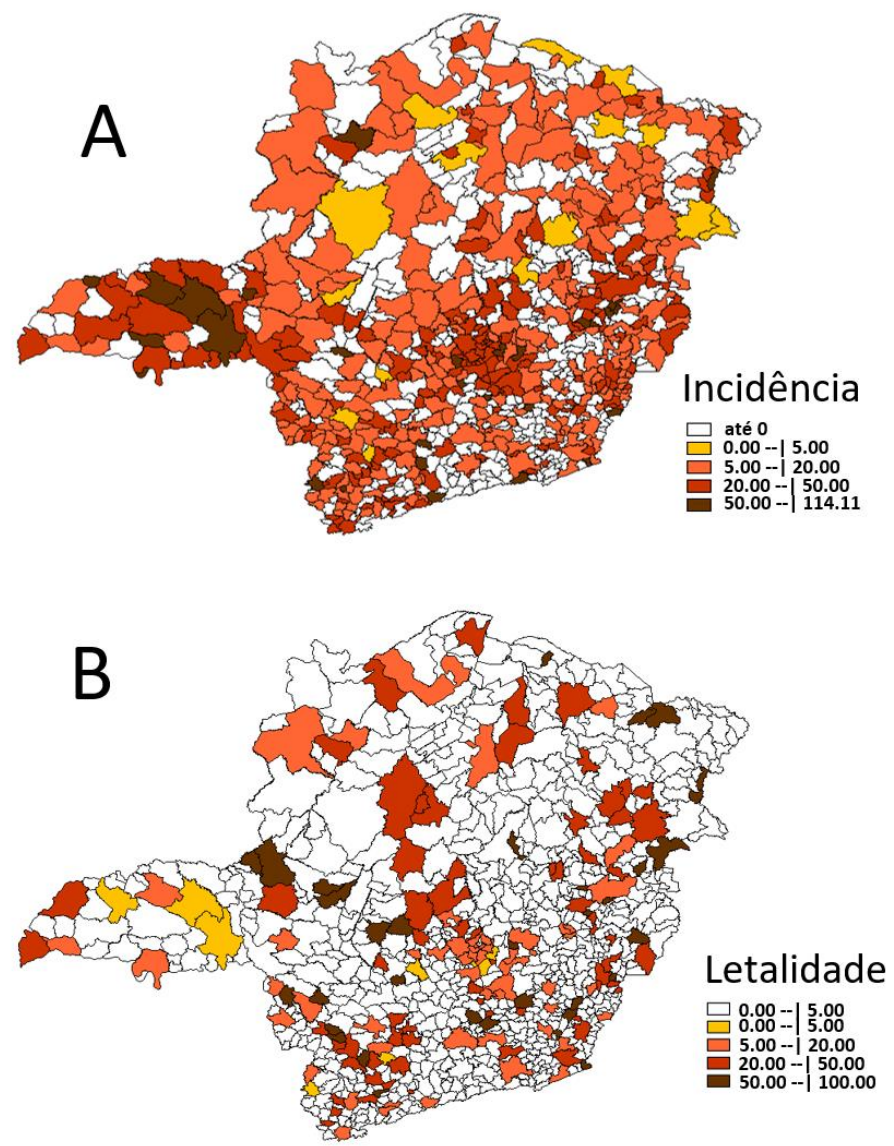

Figura 4: Incidência $(A)$ e letalidade $(B)$ dos casos notificados de meningite, por município, segundo dados do SINAN, em indivíduos de 0-14 anos, de 2010 a 2019, Minas Gerais, Brasil. 
Segundo a Tabela 2, as etiologias mais comuns foram Meningite Viral (MV), Meningite Não Especificada (MNE) e Meningite Bacteriana (MB), respectivamente, sendo as causas de óbito mais comuns às formas causadas por MB, Meningite por Streptococcus pneumoniae (MP) e MNE. A Meningococemia (MCC), de forma isolada, possui apenas 2,43\% dos casos e aproximadamente $14 \%$ dos óbitos, e somando o total de casos em que está presente, de forma conjunta ou combinada, representa menos de $5 \%$ dos casos e concentra aproximadamente $1 / 4$ das mortes. As maiores letalidades foram de 47 para MCC, 26 para MP e 25 para Meningite Meningocócica (MM) + MCC. Os sorogrupos foram confirmados em 237 casos $(54,1 \%$ dos casos notificados causados por meningococo). Os mais comuns e com mais óbitos foram, respectivamente, C, B e W135, e a maior letalidade foi observada, respectivamente, entre os sorogrupos W135 (30), Y (25) e B (21). Apareceram entre os casos também Meningite Tuberculosa (MTBC), Meningite por outras etiologias (MOE) e Meningite por Haemophilus influenzae $(\mathrm{MH})$.

Tabela 2: Número de casos, óbitos e porcentagens das notificações de meningite por etiologia e sorogrupo (para os casos causados por MCC, MM ou MM+MCC), segundo dados do SINAN, em indivíduos de 0-14 anos, de 2010 a 2019, Minas Gerais, Brasil.

\begin{tabular}{lrrrr}
\hline & \multicolumn{2}{c}{ Casos } & \multicolumn{2}{c}{ Óbitos } \\
& N & \% & \multicolumn{1}{c}{ N } & \% \\
\hline Etiologia & & & & \\
MCC & 113 & 2,43 & 54 & 14,79 \\
MM & 220 & 4,74 & 18 & 4,93 \\
MM+MCC & 105 & 2,26 & 27 & 7,40 \\
MTBC & 14 & 0,30 & 0 & 0,00 \\
MB & 755 & 16,27 & 77 & 21,10 \\
MNE & 1260 & 27,15 & 69 & 18,90 \\
MV & 1731 & 37,30 & 18 & 4,93 \\
MOE & 46 & 0,99 & 5 & 1,37 \\
MH & 101 & 2,18 & 19 & 5,21 \\
MP & 290 & 6,25 & 78 & 21,37 \\
Ignorado/ em branco & 6 & 0,13 & 0 & 0,00 \\
Total & 4641 & 100,00 & 365 & 100,00 \\
Sorogrupo (Neisseria meningitidis) & & & \\
B & 46 & 19,41 & 10 & 20,41 \\
C & 166 & 70,04 & 32 & 65,31 \\
Y & 4 & 1,69 & 1 & 2,04 \\
W135 & 20 & 8,44 & 6 & 12,24 \\
29 E & 1 & 0,42 & 0 & 0,00 \\
Total & 237 & 100,00 & 49 & 100,00 \\
\hline \multicolumn{4}{c}{}
\end{tabular}

Os critérios de confirmação mais utilizados foram o quimiocitológico (56\%), a cultura (17\%) e clínico (12\%). Outros apareceram com participações inferiores a 5\%, sendo eles em ordem decrescente: teste de aglutinação do látex (AG. látex), clínico-epidemiológico, PCR viral, bacterioscopia, outra técnica, isolamento viral, contra-imunoeletroforese (CIE) e em branco.

\section{DISCUSSÃO}

No período de 2010 a 2019, no estado de Minas Gerais, houve uma redução de $26 \%$ para o número de casos e 55\% para os óbitos. Outrossim, o ano de 2011 apresentou maior incidência da doença, seguido por uma redução nos anos seguintes e uma leve ascensão em 2017 seguida de um decréscimo em 2018 e 2019. Esta discrepância no perfil de notificações pode evidenciar uma negligência ou omissão na notificação dos casos por parte dos profissionais de saúde, 
implicando em dados pouco fidedignos à distribuição da etiologia da doença no país e dificultando a instauração de medidas preventivas posteriormente [18].

Quanto à incidência média em Minas Gerais nos anos de 2010 a 2019, foi constatado uma diminuição da incidência em $16 \%$ e da taxa de letalidade em $40 \%$. É possível verificar, a partir de estudos, que a mortalidade não está relacionada apenas à qualidade e agilidade de tratamento do doente, mas também à imunidade própria do indivíduo, virulência da cepa e o sorogrupo envolvido [19].

Com relação a quantidade de notificações, a maioria delas ocorreu em Belo Horizonte (819), Uberlândia (645) e Uberaba (668), as quais somam $38 \%$ do total de casos do estado. Nessa perspectiva, os dados encontrados são semelhantes ao estudo que analisou o perfil epidemiológico da meningite em MG, o qual apontou que a maior parte dos casos de meningite constatados residiam nas regiões do Centro e Triângulo Mineiro [20].

Estudos apontam que as diferenças sexuais influenciam no resultado de uma série de doenças infecciosas, devido à maior proporção de citocinas inflamatórias que os hormônios sexuais femininos podem gerar no combate da infecção. Essa fisiologia endócrina explica a relação de algumas infecções terem desfechos mais graves em homens do que em mulheres [21]. A relação do dimorfismo sexual com a patogenicidade de algumas doenças está de acordo com os dados analisados, já que a maioria dos casos e da mortalidade da meningite no estado de Minas Gerais foram vistos no sexo masculino.

Por outro lado, a maior letalidade em crianças entre um ano de idade, pode ser explicada pela frágil memória imunológica nessa fase da vida [21]. Nesse sentido, o presente estudo confirmou que o número de casos apresentou decréscimo com o avançar da idade e os maiores índices de letalidade são vistos em crianças menores de um ano de idade. Comparado com o estudo epidemiológico que investiga a meningite na idade pediátrica no Brasil entre 2010-2017, esses dados se confirmam em relação ao maior número de mortes em crianças desta idade [18].

Nessa investigação, observamos a ocorrência de maior número de casos na zona urbana do estado e este dado reflete um estudo epidemiológico nacional semelhante sobre a meningite feito pelo Boletim Epidemiológico do Ministério da Saúde em 2016. Aspectos urbanos como aglomeração em grandes centros e em meios de transportes implicam em uma maior disseminação de doenças cuja transmissão se dá por secreções respiratórias. Analisando em uma perspectiva de maiores avanços tecnológicos e serviços hospitalares nas zonas urbanas, se confirma a maior letalidade da meningite em zonas rurais e municípios de menor porte no estado [22].

Observa-se, ainda, na literatura que o aumento na frequência de casos de meningite tende a apresentar uma certa sazonalidade bem estabelecida, compreendendo a estação de inverno em ambos hemisférios do globo. Duas principais hipóteses têm sido levantadas para explicar essa relação. A primeira, sugere que as condições climáticas observadas nos meses mais secos de inverno poderiam ocasionar danos à nasofaringe, facilitando a invasão de certos patógenos, enquanto a segunda se relaciona com um maior aumento da transmissão bacteriana, promovido por fatores ambientais ou comportamentais [23]. Todavia, o presente estudo observou que o pico de notificações na faixa etária pediátrica em MG se deu no mês de dezembro, ou seja, em um período chuvoso, típico do verão e contrário ao que se esperaria para o restante do território brasileiro, onde o número de casos se acentua no outono e inverno [22]. Assim, pontua-se a necessidade de maiores investigações para a compreensão desse fenômeno.

A Meningite Viral (MV) foi a etiologia mais registrada no estado (37\%). Estudos a respeito da epidemiologia da meningite no território nacional demonstram que a MV é o diagnóstico mais prevalente [18, 24]. O Guia de Vigilância em Saúde chama atenção para o Enterovírus ser o agente etiológico mais frequente, predominando a transmissão fecal-oral [25]. As crianças até 9 anos são as mais prováveis de serem infectadas pelo vírus em questão, o que mostra a importância de escolas e creches promoverem a constante higienização das mãos de seus alunos [26].

A Meningite Não Especificada (MNE) aparece como a segunda etiologia mais comum (27\%) no presente estudo e ela é resultado de investigações laboratoriais inconclusivas a respeito dos agentes etiológicos. A não-especificação da meningite retrata possíveis dificuldades na coleta de amostras e no técnico-operacional dos laboratórios diagnósticos do estado de Minas 
Gerais. O Boletim Epidemiológico do Ministério da Saúde demonstra que 65,1\% das meningites registradas no Brasil de 2007 a 2016 foram a MNE, refletindo que tais problemas diagnósticos ocorrem frequentemente e, também, em uma escala nacional [27].

O diagnóstico etiológico da meningite é um dado epidemiológico importante, uma vez que é referência para ações de controle da doença e prevenção de saúde como campanhas de vacinação que previne as meningites causadas pelo $H$. influenzae, $S$. pneumoniae e o sorogrupo $\mathrm{C}$ da N. meningitidis [25]. A detecção dos agentes etiológicos também implica na escolha adequada dos tratamentos e se mostra importante para evitar efeitos adversos decorrente do uso indiscriminado de antibióticos [28].

A Meningite por Haemophilus influenzae (MH) representa apenas 2,18\% dos casos registrados no estado de Minas Gerais. Esse dado reflete os reforços do Brasil na implementação da vacina Haemophilus influenzae tipo B (Hib) no Programa Nacional de Imunização (PNI) em 1999. Após 10 anos da introdução dessa vacina, houve uma redução de $72 \%$ na incidência de casos de MH no país, especialmente na faixa etária menor de 2 anos [29].

No ano de 2010, o PNI introduziu as vacinas: pneumocócica conjugada 10-valente (VPC10) e meningocócica conjugada contra o grupo capsular $\mathrm{C}(\mathrm{MenC}-\mathrm{V})$. Evidências demonstram que a implementação dessas duas vacinas foi associada à diminuição de morte de crianças menores de 5 anos no país [30]. Na nossa análise, observamos que a Meningite por Pneumococo (MP) foi a quinta etiologia mais registrada no estado (290) e ocupa a segunda posição no maior número de óbitos e na letalidade. Diante disso, a MP tem participação significativa em desfechos fatais na faixa etária pediátrica e, por isso, a intensificação do controle da vacinação se mostra necessária no estado.

A primeira e a terceira maiores letalidades no nosso estudo foram observadas nos casos de Meningococcemia (MCC) e Meningite Meningocócica acompanhada de Meningococcemia (MM+MCC), respectivamente. Sabe-se que o Meningococo é a principal causa de Meningite Bacteriana no Brasil e que sua forma mais grave de manifestação, MCC, está associada a uma taxa de letalidade de 50\% [25]. A Doença Meningocócica (DM) acomete todas as faixas etárias, mas $50 \%$ dos casos notificados no país acometem crianças menores de 5 anos [31]. Percebe-se, então, o grande impacto da doença na faixa etária pediátrica.

No Brasil, os sorotipos da DM mais comuns são os C e B [32]. O nosso estudo segue as estatísticas nacionais, no entanto, a maior letalidade foi atribuída aos sorotipos W-135 e Y, respectivamente. Um trabalho epidemiológico conduzido no Rio Grande do Sul revelou que o segundo sorotipo mais comum do estado era o W-135 [33]. Diante disso, observa-se que a contemplação da Vacina Meningocócica ACWY (conjugada) no PNI em 2020 foi um avanço muito importante para prevenção da meningite no Brasil [34].

Mostra-se difícil avaliar a eficácia da introdução da vacina MenC-V no estado, uma vez que em apenas $54,1 \%$ dos casos de DM o sorotipo foi identificado. Esse dado chama atenção para a dificuldade laboratorial na identificação das etiologias, assim como a presença de um déficit de dados epidemiológicos que pode atrapalhar em planos de prevenção de saúde.

\section{CONCLUSÃO}

Embora suficiente para a análise epidemiológica, os resultados originados do banco de dados do SINAN sobre meningite bacteriana e viral no Estado de Minas Gerais, encontrou como limitação, a necessidade de uma adequada notificação realizada pelos profissionais de saúde. A partir dos dados aqui expostos, verificou-se que o maior número de casos de meningite na faixa etária pediátrica foi registrado em dezembro e o menor em fevereiro. O número de casos apresentou decréscimo com o avançar da idade. Além disso, em relação ao predomínio dessa patologia, observou-se uma maior incidência no sexo masculino, constatando-se, também, níveis de gravidade que variam de acordo com o agente etiológico. No estado de análise do estudo, as cidades mais afetadas foram, respectivamente, Belo Horizonte, Uberlândia e Uberaba. Os óbitos estiveram concentrados na zona urbana, porém, ao analisar o desfecho da doença em crianças oriundas da zona rural, extraiu-se uma maior taxa de letalidade. Conclui-se, portanto, que o presente estudo analisou o perfil epidemiológico dos casos de meningite bacteriana e viral 
no estado de Minas Gerais, tomando como referência o recorte pediátrico. Outrossim, que a meningite se constitui como uma doença agravante nesta faixa etária, emergindo a necessidade de uma maior racionalização dos métodos de prevenção e tratamento, bem como a formulação de políticas públicas mais eficientes.

\section{REFERÊNCIAS BIBLIOGRÁFICAS}

1. van de Beek D, Brouwer M, Hasbun R, Koedel U, Whitney CG, Wijdicks E. Community-acquired bacterial meningitis. Nature. 2016 Nov;2(1):1-20. doi: 10.1038/nrdp.2016.74

2. Shukla B, Aguilera EA, Salazar L, Wootton SH, Kaewpoowat Q, Hasbun R. Aseptic meningitis in adults and children: Diagnostic and management challenges. J Clin Virol. 2017 Sep;94(1):110-14. doi: 10.1016/j.jcv.2017.07.016

3. Tattevin P, Tchamgoué S, Belem A, Bénézit F, Pronier C, Revest M. Aseptic meningitis. Rev Neurol (Paris). 2019 Sep;175(7-8):475-80. doi: 10.1016/j.neurol.2019.07.005

4. Wright WF, Pinto CN, Palisoc K, Baghli S. Viral (aseptic) meningitis: A review. J Neurol Sci. 2019 Mar;398(X):176-183. doi: 10.1016/j.jns.2019.01.050

5. Kumar R. Aseptic meningitis: diagnosis and management. Indian J Pediatr. 2005 Jan; 72(1):57-63. doi: 10.1007/BF02760582

6. Mount HR, Boyle SD. Aseptic and bacterial meningitis: Evaluation, treatment, and prevention. Am Fam Physician. 2017 Sep;96(5):314-22.

7. Lundbo LF, Benfield T. Risk factors for community-acquired bacterial meningitis. Infect Dis. 2017 Mar;49(6):433-44. doi: 10.1080/23744235.2017.1285046

8. Hviid A, Melbye M. The epidemiology of viral meningitis hospitalization in childhood. Epidemiology. 2007 Nov;18(6):695-701. doi: 10.1097/ede.0b013e3181567d31

9. Zunt JR, Kassebaum NJ, Blake N, Glennie L, Wright C, Nichols E, et al. Global, regional, and national burden of meningitis, 1990-2016: a systematic analysis for the Global Burden of Disease Study 2016. Lancet Neurol. 2018 Nov;17(12):1061-82. doi: 10.1016/S1474-4422(18)30387-9

10. Battersby AJ, Knox-Macaulay HHM, Carrol ED. Susceptibility to invasive bacterial infections in children with sickle cell disease. Pediatr Blood Cancer. 2010 Jul;55(3):401-406. doi: $10.1002 / \mathrm{pbc} .22461$

11. Naves GRC, Dias LF, Lima NLS, De Oliveira SV, Bonito RF. Incidência dos casos de meningite na cidade de Uberaba, Minas Gerais no período de 2010 a 2017: estudo populacional. Rev Cien Saude. 2019 Oct;9(3):5-9. doi: 10.21876/rcshci.v9i3.841

12. Dos Santos ENF, Ribeiro JVF, Rezende P, Gim YKB, Santos HDH, Elias RM, et al. Comparação sobre a incidência e a letalidade de meningite bacteriana e viral na faixa etária pediátrica no estado de Mato Grosso. Cad Publ Univag. 2018;(9):1-5.

13. McGill F, Griffiths MJ, Solomon T. Viral meningitis: current issues in diagnosis and treatment. Curr Op Infect Dis. 2017 Apr;30(2):248-56. doi: 10.1097/QCO.0000000000000355

14. Tacon CL, Flower O. Diagnosis and management of bacterial meningitis in the paediatric population: A review. Emerg Med Int. 2012 Sep;2012(1):1-8. doi: 10.1155/2012/320309

15. Azevedo LCPA, Toscano CM, Bierrenbach AL. Bacterial meningitis in Brazil: baseline epidemiologic assessment of the decade prior to the introduction of pneumococcal and meningococcal vaccines. PloS One. 2013 Jun;8(6):1-8. doi: 10.1371/journal.pone.0064524

16. Romanelli RMC, Araújo CA, Dias MW, Boucinhas F, Carvalho IR, Martins NRL, et al. Etiologia e evolução das meningites bacterianas em centro de pediatria. J Pediatr. 2002 Aug;78(1):24-30. doi: $10.1590 /$ S0021-75572002000100007

17. Brasil. Ministério da Saúde, Secretaria de Vigilância em Saúde. Vigilância em Saúde no Brasil 20032009: da criação da secretaria da vigilância em saúde aos dias atuais. Bol Epidemiol [Internet]. 2019 Set;50(n.esp.): 1-154. Disponível em: http://www.rets.epsjv.fiocruz.br/biblioteca/vigilancia-em-saudeno-brasil-20032019-da-criacao-da-secretaria-de-vigilancia-em-saude

18. Santos AO, Santos FRVP, Andrade LA. Frente diagnóstica e terapêutica na neurologia 2. Ponta Grossa (Brasil): Atena Editora; 2020. Chapter 20, Perfil epidemiológico da meningite na população pediátrica das macrorregiões brasileiras entre 2010-2017. p 152-58. doi: 10.22533/at.ed.56120280120

19. Paim ACB, Gregio MM, Garcia SP. Perfil epidemiológico da meningite no estado de Santa Catarina no período de 2008 a 2018. Arq Catarin Med. 2019 Oct; 48(4):111-25.

20. Ramos CG, Sá BA, Freitas LFM, Moura JA, Lopes MVBV, Gonçalves E. Meningites bacterianas: epidemiologia dos casos notificados em Minas Gerais entre os anos de 2007 e 2017. REAS. 2019 Mar; 22:e655. doi: 10.25248/reas.e655.2019 
21. Muenchhoff M, Goulder PJR. Sex differences in pediatric infectious diseases. J Infect Dis. 2014 Jul;209(3):120-26. doi: 10.1093/infdis/jiu232

22. Brasil. Ministério da Saúde, Secretaria de Vigilância em Saúde. Situação epidemiológica da doença meningocócica, Brasil, 2007-2013. Boletim Epidemiológico. 2016;47(29):1-8.

23. Koutangni T, Crépey P, Woringer M, Porgho S, Bicaba BW, Tall H, Mueller JE. Compartmental models for seasonal hyperendemic bacterial meningitis in the African meningitis belt. Epidemiol Infect. 2018 Sep;147(e14):1-11. doi: 10.1017/S0950268818002625

24. Dazzi MC, Zatti CA, Baldissera R. Perfil dos casos de meningite ocorridas no Brasil de 2009 à 2012. Rev UNINGÁ. 2014 Sep;19(3):33-6.

25. Brasil. Ministério da Saúde, Secretaria de Vigilância em Saúde, Coordenação-Geral de Desenvolvimento da Epidemiologia em Serviços. Guia de vigilância em saúde. 3. ed. atual. Brasília (DF): Ministério da Saúde; 2019.

26. Chu S, Wang E, Liu D. A review of prevention and control for enterovirus infections in Asia. Taiwan Epidemiol Bull. 2013 Jun;49(10):101-17.

27. Brasil. Ministério da Saúde, Secretaria de Vigilância em Saúde. Meningite bacteriana não especificada no Brasil 2007-2016: desafio para a vigilância das meningites. Boletim Epidemiológico. 2019;50(3):1-8.

28. Romanelli RMC, Araújo CA, Boucinhas F, Carvalho IR, Martins NRL, Freire HBM. Etiologia e evolução das meningites bacterianas em centro de pediatria. J Pediatr. 2002 Aug;77(1):24-30. doi: 10.1590/S0021-75572002000100007

29. Azevedo LCP, Toscano CM, Bierrenbach AL. Bacterial meningitis in Brazil: Baseline epidemiologic assessment of the decade prior to the introduction of pneumococcal and meningococcal vaccines. PLoS ONE. 2013 Jun;8(6):e64524. doi: 10.1371/journal.pone.0064524

30. Bierrenbach AL, Minamisava R, Alencar AP, Alencar GP, Andrade AL. Combined effect of PCV10 and meningococcal $\mathrm{C}$ conjugate vaccination on meningitis mortality among children under five years of age in Brazil. Hum Vaccim Immunother. 2018;14(5):1138-45. doi: 10.1080/21645515.2017.1391431

31. Berezin EN. Epidemiologia da infecção meningocócica. Doença meningocócica fascículo 1 [Internet]. [São Paulo]: Sociedade Brasileira de Pediatria; nov 2015 [citado em 25 nov 2020]. Disponível em: http://www.sbp.com.br/fileadmin/user_upload/publicacoes/Folheto_Meningite_Fasciculo1_111115.pd $\mathrm{f}$

32. Batista RS, Gomes AP, Gazineo JLD, Miguel PSB, Santana LA, Oliveira L, et al. Meningococcal disease, a clinical and epidemiological review. Asian Pacific J Trop Med. 2017 Nov;10(11):1019-29. doi: 10.1016/j.apjtm.2017.10.004

33. Heuert A, Soares ALB, Silveira MM. Incidência da doença meningocócica no Rio Grande do Sul entre 2014 e 2018. Vitalle - Rev Cien Saude. 2020 Jul;32(1):76-80. doi: 10.14295/vittalle.v32i1.9421

34. Brasil. Ministério da Saúde. Informe técnico: Introdução da vacina meningocócica ACWY (conjugada) para os pacientes com Hemoglobinúria Paroxística Noturna (HPN) em uso de Exulizumabe [Internet]. Brasília (DF): Ministério da Saúde; 2020 [citado em 12 abr 2021]. Disponível em: http://portalarquivos.saude.gov.br/images/pdf/2020/marco/16/Informe-ACWY-CRIE-10022020final.pdf 